\title{
Depressed mood, glycaemic control and functional capacity in overweight/obese men with and without type 2 diabetes
}

\author{
Itamar Levinger ${ }^{1,2^{*}}$, Steve Selig ${ }^{2,3}$, George Jerums $^{4}$, Andrew Stewart ${ }^{2}$, Cadeyrn J Gaskin ${ }^{3}$ and David L Hare ${ }^{2}$
}

\begin{abstract}
Objective: To determine whether there were differences in depressed mood between overweight/obese men with and without type 2 diabetes (T2DM) and to examine any associations between depressed mood, physical functioning, and glycaemic control in overweight/obese men with and without T2DM.

Methods: Fifty seven overweight/obese men with $\left(n=19\right.$, age $\left.=54.2 \pm 7.4 \mathrm{yrs}, \mathrm{BMI}=32.3 \pm 6.7 \mathrm{~kg} \cdot \mathrm{m}^{-2}\right)$ and without T2DM ( $n=38$, age $=51.1 \pm 6.8 \mathrm{yrs}, \mathrm{BMI}=29.9 \pm 4.5 \mathrm{~kg} \cdot \mathrm{m}^{-2}, \mathrm{p}>0.05$ between groups) participated. The men completed measures of depressed mood and health-related quality of life (HRQL) and underwent the following assessments: fasting blood lipids and glucose, $\mathrm{HbA1c}$, anthropometric measurements, $\mathrm{VO}_{2 \text { peak, }}$ muscle strength, and physical function.

Results: Compared to men without T2DM, men with T2DM had higher depressed mood $\left(p=0.05, \eta^{2}=0.07\right)$, as well as lower perceived general health $\left(p<.01, \eta^{2}=0.24\right)$ and social functioning $\left(p=.01, \eta^{2}=0.10\right)$. Men with T2DM also had lower $\mathrm{VO}_{\text {2peak }}\left(21.8 \pm 5.3\right.$ versus $\left.25.8 \pm 5.4 \mathrm{ml} \cdot \mathrm{kg}^{-1} \cdot \mathrm{min}^{-1}, \mathrm{p}<.01, \eta^{2}=0.11\right)$ and muscle strength $(3.3 \pm 0.8$ versus $\left.3.7 \pm 0.7 \mathrm{~kg} \cdot \mathrm{kg}^{-1}, p=0.08, \eta^{2}=0.06\right)$, as well as being slower to complete physical performance tasks (27.2 \pm 5.2 versus $24.2 \pm 2.8 \mathrm{sec}, \mathrm{p}<0.01, \eta^{2}=0.13$ ). In those with $\mathrm{T} 2 \mathrm{DM}$, depressed mood was highly correlated with most HRQL subscales. For the combined cohort, depressed mood was correlated with fasting glucose $(r=0.31, p=0.012)$ but not the functional measures.

Conclusions: Men with T2DM have higher levels of depressed mood compared to men without T2DM. Glycaemic control, but not functional capacities, is associated with depressed mood in the study cohort.
\end{abstract}

Keywords: Aerobic power, Cardiac Depression Scale, Depression, Glycaemic control; Type 2 diabetes

\section{Introduction}

Most people with type 2 diabetes (T2DM) are overweight or obese [1] and, compared to people without diabetes, have double the risk for depression [2]. Aside from experiencing poor health, people with T2DM have higher incidence of functional limitations, particularly if they have poor glycaemic control [3].

The relationship between diabetes and depression is bidirectional $[4,5]$. Up to a point, the severity of either

\footnotetext{
* Correspondence: itamar.levinger@vu.edu.au

${ }^{1}$ Institute for Sport, Exercise and Active Living (ISEAL), School of Sport and Exercise Science, Victoria University, PO Box 14428, Melbourne, VIC 8001, Australia

${ }^{2}$ University of Melbourne and Department of Cardiology, Austin Health, Melbourne, Australia

Full list of author information is available at the end of the article
}

condition seems to be associated with the chronicity of the other. For example, in community-dwelling older adults, depressive symptoms and HbA1c levels rise in tandem until HbA1c levels reach about $8 \%$, beyond which the severity of both conditions plateau [6]. Although behavioural (e.g. diet, exercise), neurological (activation of the hypothalamic-pituitary-adrenal and sympathoadrenal systems), and pharmacological factors have been suggested to contribute to the incidence of T2DM among people with depression, evidence suggests that the relationship between T2DM and depression is maintained when these factors are taken into account [4]. Similarly, other factors that have been hypothesised to increase the incidence of depressive symptoms among people with T2DM (e.g. presence of comorbidies and 
diabetic complications) have been shown not to substantially influence the relationship between T2DM and depression $[4,7,8]$. Further exploration of biological factors may be warranted.

Associations between diabetes and physical function have been established using objective measures (e.g. activities of daily living, ADL) [9]. Being able to maintain an active lifestyle is important for preserving or improving clinical status $[10,11]$ and health related quality of life (HRQL) [12] for people with diabetes. As people with diabetes age, maintenance of ADLs takes on greater significance, because deterioration of ADLs is associated with loss of independence and increased risks of morbidity and mortality [13]. The relationship between physical function and HbA1c levels in people with T2DM is unclear $[3,13,14]$. Some studies suggest that higher $\mathrm{HbA1c}$ levels are associated with impaired physical function $[3,13]$, whilst other research found no evidence of this [14].

Compared to people without T2DM, people with T2DM have lower aerobic capacity $[15,16]$ as well as longer time to recover from exercise [17] and lower muscular strength $[18,19]$. Maintaining muscular strength is important for reducing the likelihood of functional limitations [20]. Being overweight or obese, as well as having T2DM, may make exercise more challenging, which may contribute further to loss of muscular strength and functional decline, and the cycle repeats itself.

Depression is associated with lower levels of physical [21] and social functioning [22] in people with chronic disease. In people with T2DM, the presence of complications (i.e. diabetic retinopathy, diabetic angiopathy and diabetic neuropathy) has been associated with higher prevalence and severity of both depression and functional disability (indicating lower levels of physical function) [23]. Further, people with poor self-perceived weight control had more depressive symptoms and lower physical functioning, and that self-perceived weight control was linearly related to BMI [23].

People with diabetes and co-morbid depression experience diminished HRQL [24,25]. Although relationships are thought to exist between depression and mental health components of HRQL in people with diabetes, the relationship between depression and physical functioning is not clear [24].

Evidence suggests that men and women may experience different levels of depression associated with T2DM [26]. In this study, we focused on the experiences of middle-aged men to exclude the potential effects of menopause (metabolism and psychological). The aims of the current study were (a) to determine whether there were differences in depressed mood between overweight/obese men with and without T2DM and (b) to examine the associations between depressed mood, functional measures and glycaemic control in men with and without T2DM. We hypothesized that patients with T2DM have higher depressed mood and that depressed mood would be correlated with impairment of physical function and poorer glycaemic control.

\section{Methods}

\section{Participants}

Inclusion criteria: males with and without $\mathrm{T} 2 \mathrm{DM} \geq 40 \mathrm{yr}$ not participating in regular aerobic or resistance exercise for the previous six months; Exclusion criteria: symptomatic cardiovascular disease or musculoskeletal conditions that impaired physical activity. Participants were overweight or obese men with $(\mathrm{n}=19)$ or without $(\mathrm{n}=38)$ T2DM (Table 1). Participants were on a range of medications (Table 1).

The Victoria University and Austin Health Human Research Ethics Committees approved the study protocol. The participants provided informed consent before becoming involved with the study.

\section{Measures \\ Demographics}

Participants were asked to provide their ages, what medications they were taking, and for those with T2DM, the known duration of the disease.

\section{Blood measures}

A blood sample was collected after overnight fasting. Blood was analysed (SYNCHRON LX ${ }^{\circledR}$ System/Lxi725, Beckman Coulter Inc, CA, USA) for triglyceride (Trig), high-density lipoprotein (HDL), glucose, and HbA1c.

\section{Blood pressure}

Blood pressure was measured using a mercury sphygmomanometer, as has been described previously [27].

\section{Anthropometric measurements}

Height was measured with participants standing barefoot on a stadiometer $( \pm 0.5 \mathrm{~cm})$. Weight was measured with participants wearing just underwear while standing on a calibrated scale (August Sauter GmbH, Germany) $( \pm 0.05 \mathrm{~kg})$.

\section{Aerobic power}

The full protocol for measuring aerobic power has been described previously [27]. In brief, aerobic power $\left(\mathrm{VO}_{2 \text { peak }}\right)$ was assessed using a sign and symptom limited graded exercise test on Cybex MET 100 cycle (Cybex Metabolic Systems, Ronkonkoma, NY, USA). $\mathrm{VO}_{2}$ for each $15 \mathrm{sec}$ interval was measured by gas analysis (Medgraphics, Cardio2 and CPX/D System with Breezeex Software, 142090-001, Revia, MN, USA). 
Table 1 Comparison between overweight/obese men without diabetes $(n=38)$ and overweight/obese men with diabetes $(n=19)$ on demographics and medications

\begin{tabular}{|c|c|c|c|c|}
\hline & Men without Diabetes & Men with Diabetes & $\eta^{2}$ & $p$ \\
\hline Demographics & -———- & -——-- & -———- & -——- \\
\hline Age (yrs) & $51.1 \pm 6.8$ & $54.2 \pm 7.4$ & .04 & .12 \\
\hline Height (cm) & $175.9 \pm 6.7$ & $175.9 \pm 5.8$ & .00 & .99 \\
\hline Mass $(\mathrm{kg})$ & $92.4 \pm 14.0$ & $100.2 \pm 23.0$ & .04 & .12 \\
\hline BMI (kg.m-2) & $29.9 \pm 4.5$ & $32.3 \pm 6.7$ & .04 & .12 \\
\hline Fasting Glucose $(\mathrm{mmol} \cdot \mathrm{L}-1)$ & $5.4 \pm 0.5$ & $8.1 \pm 1.9$ & .54 & $<.01^{*}$ \\
\hline $\mathrm{HbA1c}(\%)$ & $5.5 \pm 0.3$ & $6.8 \pm 0.9$ & .51 & $<.01^{*}$ \\
\hline $\mathrm{HbA1c}(\mathrm{mmol} \cdot \mathrm{mol}-1)$ & $37 \pm 4$ & $50 \pm 10$ & .51 & $<.01^{*}$ \\
\hline Trig $(\mathrm{mmol} \cdot \mathrm{L}-1)$ & $1.5 \pm 0.9$ & $1.7 \pm 0.8$ & .02 & .35 \\
\hline $\mathrm{HDL}(\mathrm{mmol} \cdot \mathrm{L}-1)$ & $1.2 \pm 0.4$ & $1.0 \pm 0.2$ & .08 & $.04^{*}$ \\
\hline SBP $(\mathrm{mmHg})$ & $130.0 \pm 14.3$ & $133.7 \pm 16.4$ & .01 & .38 \\
\hline $\mathrm{DBP}(\mathrm{mmHg})$ & $86.6 \pm 11.0$ & $86.2 \pm 13.3$ & .00 & .90 \\
\hline Known duration of T2DM (yrs) & -———- & $2.5 \pm 3.6$ & -———- & -——- \\
\hline Medications & -——-— & -———- & -———- & -——- \\
\hline Calcium channel blockers & 0 & 3 & -———- & -———- \\
\hline ACE inhibitors & 5 & 4 & -———- & -——- \\
\hline Beta-blockers & 2 & 3 & -——— & -——— \\
\hline Cholesterol lowering medication & 2 & 11 & -———- & -——— \\
\hline Glucose lowering medication & 0 & 12 & -———- & -——- \\
\hline Angiotensin II receptor antagonist & 1 & 4 & -——-— & -——- \\
\hline Platelet inhibitor & 0 & 2 & -———- & -———- \\
\hline Anti-depressants & 2 & 3 & -——- & -——- \\
\hline Aspirin & 0 & 6 & -———- & -——- \\
\hline
\end{tabular}

${ }^{*} \mathrm{p}<.05$. BMI (body mass index), HbA1c (glycosylated-haemoglobin), Trig (triglyceride), HDL (high density lipoprotein), SBP (systolic blood pressure), DBP (diastolic blood pressure). Data are mean \pm SD.

\section{Physical function}

The Physical Performance Test (PPT) was used as an objective measure of physical function. The full protocol of the PPT has been described previously [27]. In brief, the PPT included four functional mobility tasks, including a 15 meters rapid walking test; a timed up-and-go test where participants were required to rise from a standard chair, walk 3 meters, and return to a seated position on the chair; and stair climbing and stair descending tests. All tests were timed (sec). The PPT score was the sum of the fastest times for each of the four tests.

\section{Muscular strength}

Muscular strength was evaluated using the one repetition maximum method for chest press and leg press, as described previously [27]. Muscle strength was calculated as the sum of weight lifted in the two exercises, and is expressed as relative to body mass.

\section{Depressed mood}

The Cardiac Depression Scale (CDS) was used as a measure of depressed mood in this populations as many people with T2DM also experience co-morbid cardiovascular disease or are at a high risk of developing cardiovascular disease The CDS contains 26 items, to which participants responded on a 7-point Likert scale [28]. Higher scores are indicative of more severely depressed mood. Scores $\geq 95$ may be indicative of major depression [29]. The CDS is a reliable tool to assess depressive symptoms in people at a high risk of developing T2DM with a Cronbach's alpha $=0.84$ and is sensitive for changes in depressive symptoms post-exercise training [30].

\section{Health-related quality of life}

The SF-36 [31] was used to measure HRQL. This instrument has eight subscales: physical functioning, role limitations-physical, role limitations-emotional, energy/ fatigue, emotional well-being, social functioning, pain, and general health. The SF36 is well accepted and one of the most used questionnaires to assess HRQL in many clinical and healthy populations

\section{Statistical analyses}

Where appropriate, data are reported as mean \pm standard deviation (SD). An analysis of variance (ANOVA) 
was used to determine whether there were differences between men with and without T2DM with respect to their scores on the measures of physical function, HRQL, depressed mood, aerobic power, and muscular strength. In addition to statistical significance, effect sizes for the difference between the two conditions, in the form of $\eta^{2}$, were calculated. $\eta^{2}$ values provide the proportion of variability in a dependent variable that can be explained by the independent variable. Although $\eta^{2}$ values for differences on physical measures vary widely (i.e., between 0 and 1), on social and psychological measures (e.g., depression, HRQL) small, medium, and large effects are $0.01,0.06$, and 0.14 , respectively [32]. Pearson's product moment correlations were calculated to investigate the relationships between depressed mood and functional measures, HRQL, and glycaemic control. Although correlation coefficients ( $r$ ) can vary widely when physical measures are being correlated (between -1 and 1), on social and psychological measures small, medium, and large effects are 0.1, 0.3, and 0.5, respectively [32].

All statistical analyses were conducted at the 95\% level of significance and data reported as mean \pm standard deviation $(\mathrm{SD})$.

\section{Results}

Men with T2DM had higher fasting glucose and HbA1c levels, and slightly lower HDL levels, compared to those without T2DM (Table 1). There were no significant differences between men with and without T2DM; however, with respect to age, height, mass, BMI, triglycerides, and systolic and diastolic blood pressure. Men with T2DM performed the physical performance tasks more slowly, reported poorer perceptions of their general health and social functioning and higher levels of depressed mood, and recorded lower aerobic power (Table 2). Depressed mood was correlated with several aspects of HRQL (general health, energy/fatigue, and emotional well-being) in men with and without T2DM (Table 3). For each group separately there were no significant correlations between depressed mood and physical function, aerobic power, muscular strength, and glycaemic control. However, in the entire cohort (pooled data), depressed mood correlated with fasting glucose $(\mathrm{r}=0.31, \mathrm{p}=0.012)$ but not aerobic power, muscle strength or the capacity to perform ADLs (data adjusted for BMI). There was no correlation between depressed mood and BMI (adjusted and not adjusted for fasting glucose).

\section{Discussion}

This study showed that men with T2DM have higher levels of depressed mood than those without T2DM. T2DM explained 7\% of the variance in depressed mood scores, which is a moderately large effect for a psychological measure [32]. This finding supports previous work $[2,33]$ and suggests that clinicians need to be vigilant for the presence of co-morbid symptoms of depression when treating men with T2DM. This is supported by evidence that the relationship between diabetes and depression is bidirectional $[4,5]$.

Consistent with previous work that has evaluated aerobic capacity $[15,16,19]$ and strength $[18,19]$ for people with T2DM, the present study showed that men with T2DM had lower aerobic capacity and strength than men without T2DM. In addition, men with T2DM had

Table 2 Comparison between overweight/obese men without diabetes $(n=38)$ and overweight/obese men with diabetes $(n=19)$ on physical function, health-related quality of life, depressed mood, aerobic capacity, and muscular strength

\begin{tabular}{|c|c|c|c|c|}
\hline & Men without Diabetes & Men with Diabetes & $\eta^{2}$ & p \\
\hline Physical Function & -———- & -———- & -——- & -——- \\
\hline Physical performance (secs) & $24.2 \pm 2.8$ & $27.3 \pm 5.2$ & .13 & $<.01^{*}$ \\
\hline Health-Related Quality of Life & -——— & -———- & -——- & -——- \\
\hline Physical functioning & $87.6 \pm 12.0$ & $82.1 \pm 12.4$ & .05 & .11 \\
\hline Role limitations - physical & $81.6 \pm 32.2$ & $76.3 \pm 33.8$ & .01 & .57 \\
\hline Role limitations - emotional & $88.6 \pm 27.2$ & $82.4 \pm 35.8$ & .01 & .47 \\
\hline Energy/fatigue & $62.4 \pm 14.5$ & $60.8 \pm 14.5$ & .00 & .70 \\
\hline Emotional well-being & $79.5 \pm 11.9$ & $76.0 \pm 13.5$ & .02 & .32 \\
\hline Social functioning & $91.6 \pm 13.9$ & $79.7 \pm 21.3$ & .10 & $.01^{*}$ \\
\hline Pain & $72.9 \pm 21.9$ & $80.3 \pm 18.0$ & .03 & .21 \\
\hline General health & $69.1 \pm 17.0$ & $49.3 \pm 16.9$ & .24 & $<.01^{*}$ \\
\hline Depressed mood & $72.3 \pm 20.1$ & $83.9 \pm 21.1$ & .07 & .05 \\
\hline Aerobic Power $\left(\mathrm{VO}_{\text {2peak }}\right)$ & $25.8 \pm 5.4$ & $21.8 \pm 5.3$ & .11 & $<.01^{*}$ \\
\hline Muscular Strength $(\mathrm{kg} \cdot \mathrm{kg})$ & $3.7 \pm 0.7$ & $3.3 \pm .8$ & .06 & .08 \\
\hline
\end{tabular}

${ }^{*} \mathrm{p}<.05$. Data are mean \pm SD. 
Table 3 Relationships between depressed mood and physical function, health-related quality of life, aerobic power, muscular strength, and glycaemic control in overweight and obese men with and without T2DM

\begin{tabular}{|c|c|c|c|c|}
\hline & \multicolumn{2}{|c|}{ Depressed Mood in Men without Diabetes } & \multicolumn{2}{|c|}{ Depressed Mood in Men with Diabetes } \\
\hline & $r$ & $\mathrm{p}$ & $r$ & $\mathrm{p}$ \\
\hline Physical Function & -—-—- & -—-— & $-1---$ & -———- \\
\hline Physical performance & .15 & .18 & -.07 & .39 \\
\hline Health-Related Quality of Life & -———- & -———- & -———- & -———— \\
\hline Physical functioning & -.40 & $<.01^{*}$ & -.35 & .07 \\
\hline Role limitations - physical & -.47 & $<.01^{*}$ & -.58 & $<.01^{*}$ \\
\hline Role limitations - emotional & -.16 & .17 & -.54 & $<.01^{*}$ \\
\hline Energy/fatigue & -.67 & $<.01^{*}$ & -.85 & $<.01^{*}$ \\
\hline Emotional well-being & -.67 & $<.01^{*}$ & -.56 & $<.01^{*}$ \\
\hline Social functioning & -.31 & .03 & -.80 & $<.01^{*}$ \\
\hline Pain & -.38 & $<.01^{*}$ & -.67 & $<.01^{*}$ \\
\hline General health & -.70 & $<.01^{*}$ & -.34 & .08 \\
\hline Aerobic Power & -.17 & .16 & .26 & .15 \\
\hline Muscular Strength & -.23 & .08 & .20 & .21 \\
\hline Glycaemic Control & .08 & .33 & -.04 & .44 \\
\hline
\end{tabular}

${ }^{*} \mathrm{p}<.05$.

lower physical function scores (both objective measures and self-perceived). Taken together, these findings emphasise the value for people with T2DM to undertake regular physical activity.

In both men with and without T2DM, depressed mood was strongly associated with subjective measures of functioning (subscales of HRQL) but weakly related to objective measures of functioning (physical performance, aerobic power, muscular strength). This finding may mean that men with depressed mood may perceive their physical functioning to be worse than is evidenced through objective measures, particularly those with T2DM. Such perceptions may lead to lower self-efficacy and discourage people with T2DM from undertaking regular exercise and physical activity that they are capable of performing, which may, in turn, have detrimental effects on clinical, functional and psychosocial wellbeing. For this reason, an interventional study is warranted for people with T2DM that aims to relieve symptoms of depression and improve self-efficacy for exercise; outcome measures could include effects on long term exercise participation, physical functioning and HRQL.

Depressed mood was strongly correlated with social functioning in men with T2DM. The relationship between depression and social function is often significant and pervasive, but is frequently underappreciated [34]. As part of treatments for both T2DM and depression, clinicians should enquire about the social lives of men with diabetes and work with them to build on their relationships with others.
In men with diabetes, a large correlation was also found between depressed mood and pain. Although causation cannot be determined from this study, it seems likely that pain could exacerbate depressed mood as it may limit a person's physical functioning and willingness to exercise. With at least one quarter of people with diabetes affected by distal symmetric polyneuropathy [35], with which people often experience debilitating neuropathic pain, clinicians need to account for pain as a cause for depressed mood in their patients.

There is evidence that for people with T2DM, depression is associated with increased insulin resistance and poor glycaemic control, whilst the links between glycaemic control and functional capacities are weaker for people with T2DM [36]. The current study supports this finding. Fasting glucose, but not objective measures of physical function, was correlated with depressed mood. This may have important implications for the prevention, and management of depression in this population. It highlights that improvements in glycaemic control may not only have significant clinical benefits, such as reductions in diabetic complications [37], but may also have psychological benefits, and vice-versa. The current study has several potential limitations including the cross-sectional nature of the study, a relative small sample size and that these findings may not generalize to women or other demographic groups.

In conclusion, men with T2DM have higher levels of depressed mood and lower functional capacity, as measured by both objective and subjective tools, compared 
to men without diabetes. Increased fasting blood glucose levels are associated with increased depressive symptoms.

\section{Competing interests}

The authors declare that they have no conflict of interest.

\section{Authors' contribution}

IL participated in the concept and design, data collection, analysis, interpretation of the results and drafting the paper. SS participated in the concept and design, interpretation of the results, review of the paper and supervision. GJ participated in the concept and design, interpretation of the results and critical review of the paper. AS participated in data interpretation and drafting the paper. CJG participated in data analysis, interpretation of the results and drafting the paper. DLH participated in the concept and design, interpretation of the results and critical review of the paper. All authors read and approved the final manuscript.

\section{Acknowledgements}

Dr Itamar Levinger is a Heart Foundation Postdoctoral Research Fellow (PR $11 \mathrm{M}$ 6086).

\section{Author details}

${ }^{1}$ Institute for Sport, Exercise and Active Living (ISEAL), School of Sport and Exercise Science, Victoria University, PO Box 14428, Melbourne, VIC 8001, Australia. ${ }^{2}$ University of Melbourne and Department of Cardiology, Austin Health, Melbourne, Australia. ${ }^{3}$ Centre for Exercise and Sports Science, School of Exercise \& Nutrition Sciences, Deakin University, Melbourne, Australia. ${ }^{4}$ University of Melbourne and Department of Endocrinology, Austin Health, Melbourne, Australia.

Received: 24 August 2012 Accepted: 20 November 2012

Published: 21 November 2012

\section{References}

1. Groop LC, Tuomi T: Non-insulin-dependent diabetes mellitus-a collision between thrifty genes and an affluent society. Ann med 1997, 29:37-53.

2. Anderson RJ, Freedland KE, Clouse RE, Lustman PJ: The prevalence of comorbid depression in adults with diabetes: a meta-analysis. Diabetes Care 2001, 24:1069-1078

3. de Rekeneire N, Resnick HE, Schwartz AV, Shorr RI, Kuller LH, Simonsick EM, Vellas B, Harris TB: Diabetes is associated with subclinical functional limitation in nondisabled older individuals: the health, aging, and body composition study. Diabetes Care 2003, 26:3257-3263.

4. Golden SH, Lazo M, Carnethon M, Bertoni AG, Schreiner PJ, Diez Roux AV, Lee HB, Lyketsos C: Examining a bidirectional association between depressive symptoms and diabetes. JAMA 2008, 299:2751-2759.

5. Pan A, Lucas M, Sun Q, van Dam RM, Franco OH, Manson JE, Willett WC, Ascherio A, Hu FB: Bidirectional association between depression and type 2 diabetes mellitus in women. Arch Intern Med 2010, 170:1884-1891.

6. Hamer M, Batty GD, Kivimaki M: Haemoglobin A1c, fasting glucose and future risk of elevated depressive symptoms over 2 years of follow-up in the English Longitudinal Study of Ageing. Psychol Med 2011, 41:1889-1896.

7. Vileikyte L, Leventhal H, Gonzalez JS, Peyrot M, Rubin RR, Ulbrecht JS, Garrow A, Waterman C, Cavanagh PR, Boulton AJ: Diabetic peripheral neuropathy and depressive symptoms: the association revisited. Diabetes Care 2005, 28:2378-2383.

8. Gonzalez JS, Safren SA, Cagliero E, Wexler DJ, Delahanty L, Wittenberg E, Blais MA, Meigs JB, Grant RW: Depression, self-care, and medication adherence in type 2 diabetes: relationships across the full range of symptom severity. Diabetes Care 2007, 30:2222-2227.

9. Curtis B, Hayes RP, Fehnel S, Zografos L: Assessing the effect of weight and weight loss in obese persons with type 2 diabetes. Diabetes Metab Syndr Obes 2008, 1:13-23.

10. Eriksson KF, Lindgarde F: Prevention of type 2 (non-insulin-dependent) diabetes mellitus by diet and physical exercise. The 6-year malmo feasibility study. Diabetologia 1991, 34:891-898.

11. Umpierre D, Ribeiro $P A B$, Kramer CK, Leitão CB, Zucatti ATN, Azevedo MJ, Gross JL, Ribeiro JP, Schaan BD: Physical activity advice only or structured exercise training and association with $\mathrm{HbA} 1 \mathrm{c}$ levels in type 2 diabetes. JAMA 2011, 305:1790-1799.

12. Chyun DA, Melkus GD, Katten DM, Price WJ, Davey JA, Grey N, Heller G, Wackers FJT: The association of psychological factors, physical activity, neuropathy, and quality of life in type 2 diabetes. Bio Res Nur 2006, 7:279-288

13. Bossoni S, Mazziotti G, Gazzaruso C, Martinelli D, Orini S, Solerte SB, Romanelli G, Giustina A: Relationship between instrumental activities of daily living and blood glucose control in elderly subjects with type 2 diabetes. Age Ageing 2008, 37:222-225.

14. Kalyani RR, Saudek CD, Brancati FL, Selvin E: Association of diabetes, comorbidities, and $\mathrm{A} 1 \mathrm{C}$ with functional disability in older adults: results from the national health and nutrition examination survey (NHANES), 1999-2006. Diabetes Care 2010, 33:1055-1060.

15. Katoh J, Hara Y, Kurusu M, Miyaji J, Narutaki K: Cardiorespiratory function as assessed by exercise testing in patients with non-insulin-dependent diabetes mellitus. J Int Med Res 1996, 24:209-213.

16. Fang ZY, Sharman J, Prins JB, Marwick TH: Determinants of exercise capacity in patients with type 2 diabetes. Diabetes Care 2005, 28:1643-1648

17. Levinger I, Varley M, Jerums G, Hare DL, Selig S: Oxygen (O2) kinetics during early recovery from peak exercise in patients with Type 2 diabetes. Diabet Med 2011, 28:612-617.

18. Cetinus E, Buyukbese MA, Uzel M, Ekerbicer $H$, Karaoguz A: Hand grip strength in patients with type 2 diabetes mellitus. Diabetes Res Clin Pract 2005, 70:278-286.

19. Özdirenç M, Biberğlu S, Özcan A: Evaluation of physical fitness in patients with type 2 diabetes mellitus. Diabetes Res Clin Pract 2003, 60:171-176.

20. Brill PA, Macera CA, Davis DR, Blair SN, Gordon N: Muscular strength and physical function. Med Sci Sports Exerc 2000, 32:412-416.

21. Shen B-J, Eisenberg SA, Maeda U, Farrell KA, Schwarz ER, Penedo FJ, Bauerlein EJ, Mallon S: Depression and anxiety predict decline in physical health functioning in patients with heart failure. Ann Behav Med 2011, 41:373-382.

22. Kirchner T, Lara S: Stress and depression symptoms in patients with multiple sclerosis: the mediating role of the loss of social functioning Acta Neurol Scand 2011, 123:407-413.

23. Schmitz N, Messier L, Nitka D, Ivanova A, Gariepy G, Wang J, Malla A, Boye R, Lesage A, Strychar I: Factors associated with disability and depressive symptoms among individuals with diabetes: A community study in Quebec. Psychosom J Consul Lia Psyc 2011, 52:167-177.

24. Ali S, Stone M, Skinner TC, Robertson N, Davies M, Khunti K: The association between depression and health-related quality of life in people with type 2 diabetes: A systematic literature review. Diabetes Metab Res Rev 2010, 26:75-89.

25. Schram MT, Baan CA, Pouwer F: Depression and quality of life in patients with diabetes: A systematic review from the European depression in diabetes (EDID) research consortium. Curr Diabetes Rev 2009, 5:112-119.

26. Clarke DM, Currie KC: Depression, anxiety and their relationship with chronic diseases: a review of the epidemiology, risk and treatment evidence. Med J Aust 2009, 190:S54-S60.

27. Levinger I, Goodman C, Hare DL, Jerums G, Selig S: The effect of resistance training on functional capacity and quality of life in individuals with high and low numbers of metabolic risk factors. Diabetes Care 2007, 30:2205-2210.

28. Hare DL, Davis CR: Cardiac Depression Scale: validation of a new depression scale for cardiac patients. J Psychosom Res 1996, 40:379-386.

29. Shi WY, Stewart AG, Hare DL: Major depression in cardiac patients is accurately assessed using the cardiac depression scale. Psychother Psychosom 2010, 79:391-392

30. Levinger I, Selig S, Goodman C, Jerums G, Stewart A, Hare DL: Resistance training improves depressive symptoms in individuals at high risk for type 2 diabetes. J Strength Cond Res 2011, 25:2328-2333.

31. Ware JE: SF-36 physical and mental health summary scales: a manual for users of version 1. 2nd edition. Boston, MA: The Health Institute, New England Medical Center; 1997.

32. Cohen J: Statistical power analysis for the behavioral sciences. 2nd edition. New Jersey: Lawrence Erlbaum Ass. Publishers; 1988.

33. Nichols GA, Brown JB: Unadjusted and adjusted prevalence of diagnosed depression in type 2 diabetes. Diabetes Care 2003, 26:744-749. 
34. Hirschfeld RMA, Montgomery SA, Keller MB, Kasper S, Schatzberg AF, Möller $H-J$, Healy D, Baldwin D, Humble M, Versiani M, et al: Social functioning in depression: A review. J Clin Psychiatry 2000, 61:268-275.

35. Ziegler D: Treatment of diabetic neuropathy and neuropathic pain. Diabetes Care 2008, 31:S255-S261.

36. Wagner J, Allen NA, Swalley LM, Melkus GD, Whittemore R: Depression, depression treatment, and insulin sensitivity in adults at risk for type 2 diabetes. Diabetes Res Clin Pract 2009, 86:96-103.

37. Girach A, Manner D, Porta M: Diabetic microvascular complications: can patients at risk be identified? A review. Int J Clin Pract 2006, 60:1471-1483.

doi:10.1186/1758-5996-4-46

Cite this article as: Levinger et al: Depressed mood, glycaemic control and functional capacity in overweight/obese men with and without type 2 diabetes. Diabetology \& Metabolic Syndrome 2012 4:46.

\section{Submit your next manuscript to BioMed Central and take full advantage of:}

- Convenient online submission

- Thorough peer review

- No space constraints or color figure charges

- Immediate publication on acceptance

- Inclusion in PubMed, CAS, Scopus and Google Scholar

- Research which is freely available for redistribution 